\title{
Indian Journal of Microbiology: striving for excellence
}

It gives me immense pleasure to write this editorial about the progress that Indian Journal of Microbiology (IJM) has made since it first went online with Springer India Pvt. Ltd. in June 2007. The past two years have been very crucial in improvement of the quality of articles published in IJM. Since the journal became online, we have witnessed an increase in the number of submissions by several folds. The difference now seems exceptional as the manuscripts presenting archival and redundant data have given way to articles with latest and valuable data.

We started with a 41 member Editorial board in 2007 and today the number has grown to 70 Editors and 474 Reviewers, comprising distinguished Microbiologists with extensive research and diagnostic experience from within and outside India who are continually engaged in improving the journal and its rating. There has been substantial improvement in the national and international readership of the journal and we have seen a rise in the number of international contributors too. IJM is now listed in 64 abstracting services. I am overwhelmed to share with all our colleagues and readers that Indian Journal of Microbiology is now included in Science Citation Index Expanded (SCI-E) starting 2008, this means the journal will get an impact factor for 2010 that will be published in June 2011.

There is no denial of the fact that we have seen significant improvement in the quality of articles submitted to IJM and all efforts are made to remain up-to-date and in confirmation with current thinking in Microbiology. It is my continued request to our Editors, Reviewers and Authors to contribute original research articles and observations to the journal. Comments, re-interpretations and contributions are always welcome from the readers. Active involvement and inputs from young minds are also highly desirable. We are always looking for in-depth articles on virtually any topic pertaining to microorganisms.

We are currently witnessing rapid progress in the field of Microbiology. Advancements in diverse areas of technology have brought into picture new equipment and techniques that have revolutionized current research practices. For instance, the quick identification of the causative agent of Swine flu-H1N1 virus (See News and views, current issue) that has affected about 2500 people in the US alone has been possible due to such advancements only.

We strive for making the Indian Journal of Microbiology a vehicle for objective, open and peer-reviewed publication and discussion of all aspects of Microbiology. It needs to be further strengthened with quality inputs as well as maintaining high standards.
Prof. Rup Lal

Editor-in-Chief 